\title{
The role of lung imaging in pulmonary embolism
}

\author{
Fred S. MishKIN \\ M.D.
}

\author{
PhILIP M. JOHNSON \\ M.D.
}

\begin{abstract}
Division of Nuclear Medicine, Department of Radiology, Martin Luther King Jr, General Hospital, Los Angeles, California, and The College of Physicians and Surgeons, Columbia University, New York
\end{abstract}

\begin{abstract}
Summary
The advantages of lung scanning in suspected pulmonary embolism are its diagnostic sensitivity, simplicity and safety. The ability to delineate regional pulmonary ischaemia, to quantitate its extent and to follow its response to therapy provides valuable clinical data available by no other simple means. The negative scan effectively excludes pulmonary embolism but, although certain of its features favour the diagnosis of embolism, the positive scan inherently lacks specificity and requires angiographic confirmation when embolectomy, caval plication or infusion of a thrombolytic agent are contemplated. The addition of simple ventilation imaging techniques with radioxenon overcomes this limitation by providing accurate analog estimation or digital quantitation of regional ventilation : perfusion (V/Q) ratios fundamental to understanding the pathophysiologic consequences of embolism and other diseases of the lung.
\end{abstract}

THE conventional perfusion lung scan, utilizing a particulate radioactive tracer, owes its pre-eminent role in evaluating suspected pulmonary embolism to its sensitivity, safety and simplicity and to the insensitivity, non-specificity or morbidity that characterize alternate methods of diagnosis (Szucs et al., 1971). Careful post-mortem angiography and dissection clearly indicate a striking inability to establish the diagnosis of pulmonary embolism during life. In one study, evidence of pulmonary embolism was found in more than $60 \%$ of consecutive necropsies, yet less than $10 \%$ of these cases had been diagnosed clinically (Freiman, Suyemoto \& Wessler, 1965). Another study showed that pulmonary embolism was the commonest cause of death, occurring in $26 \%$ of post-mortem studies; yet in less than half had the diagnosis been confirmed prior to necropsy (Smith, Dexter \& Dammon, 1965).

Introduction of lung scanning during the past decade not only provides much greater diagnostic sensitivity but also furnishes an unrivalled means for delineating the natural history of pulmonary thromboembolism and its response to therapy. Recently, techniques using inert radioactive gases have proved valuable in establishing the aetiology of regional alterations of perfusion, thus overcoming the non-specificity of the positive perfusion scan. Appropriate utilization of lung scanning requires knowledge of the principles upon which it is based, its advantages and limitations and the patho-physiologic events responsible for altering the regional distribution of pulmonary arterial blood flow (Moser \& Miale, 1968).

\section{Rationale \\ Particulate tracers}

Intravenously injected radioactive particles averaging $15-35 \mu \mathrm{m}$ in diameter exceed the mean 7-9 $\mu \mathrm{m}$ diameter of the pulmonary capillaries and thus become trapped in the lung. In the absence of abnormal pulmonary-systemic shunting, $80-90 \%$ of such particles temporarily lodge in the pulmonary arteriolo-capillary bed. There is sufficient mixing with right heart blood to assure a uniform concentration of particles in the blood destined for the lung and little removal of the particles takes place during the initial minutes following injection, the period of study. The amount of material in any region of the lung equals the blood flow to that region multiplied by the concentration of the material in the blood. Since activity is proportional to the amount of material present, measuring the radioactivity in a given region of the lung provides a measure of fractional pulmonary blood flow received by that region, although actual volume or total pulmonary blood flow cannot be measured by this technique (Fig. 1) (Wagner et al., 1964).

That particulate radioactivity per unit volume reliably measures fractional regional blood flow has been shown by a variety of techniques. There is a constant ratio between the number of particles and of labelled red cells per unit mass of lung (Tow et al., 1966). Excellent correlation occurs between quantitative scanning and differential spirometry in estimating the partition of blood flow between the two lungs. The lung scan and radioactive gas techniques applied to quantitating the effects of posture and respiratory phase on regional pulmonary arterial blood flow give 

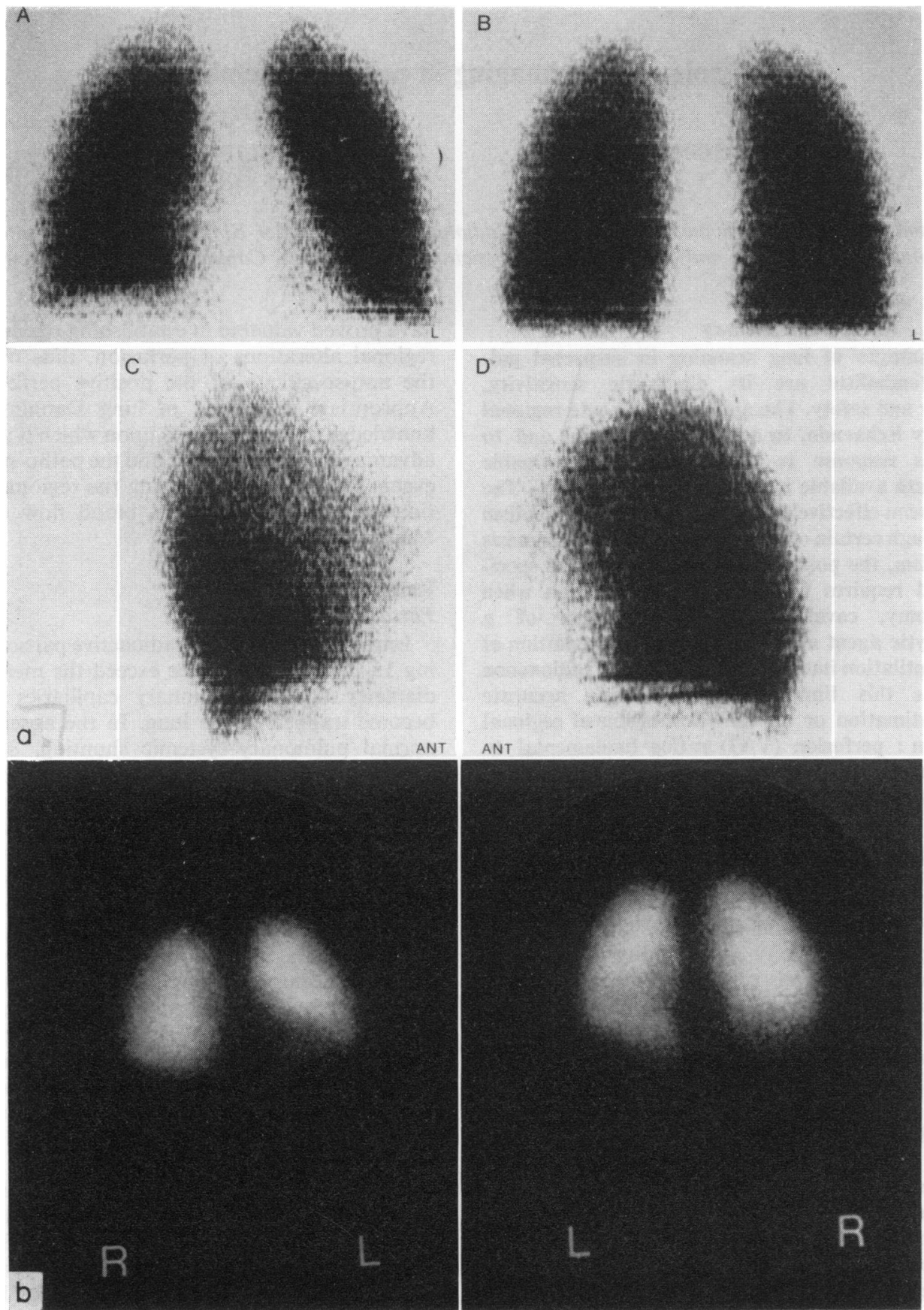

Fig. 1. (a) Normal perfusion lung scan in anterior (A), posterior (B), right lateral (C) and left lateral (D) views using a dual-headed rectilinear scanner. (b) Normal perfusion lung image using ${ }^{\circ 0 \mathrm{~m} T c-m a c r o a g g r e g a t e s}$ in anterior (left) and posterior (right) views obtained with a scintillation camera fitted with diverging collimator. 
the same results. Radioautography shows that larger particles fragment before lodging in the arterioles and capillaries.

The particles reflect the distribution of blood flow at the time of injection and not necessarily at the time of scanning. Thus, injection of particles with the patient upright results in a scan that reflects blood flow in the upright position, in spite of the fact that the actual imaging is performed with the patient supine (Fig. 2). Manoeuvres which would be difficult to sustain throughout the entire time required for imaging may be more conveniently carried out during or just prior to injection. For example, in order to obviate the effects of regional hypoventilation, $100 \%$ oxygen may be administered for a half-hour on the ward, the particles injected, following which oxygen administration can be discontinued and the patient brought to the nuclear medicine laboratory for

Upright injection

a

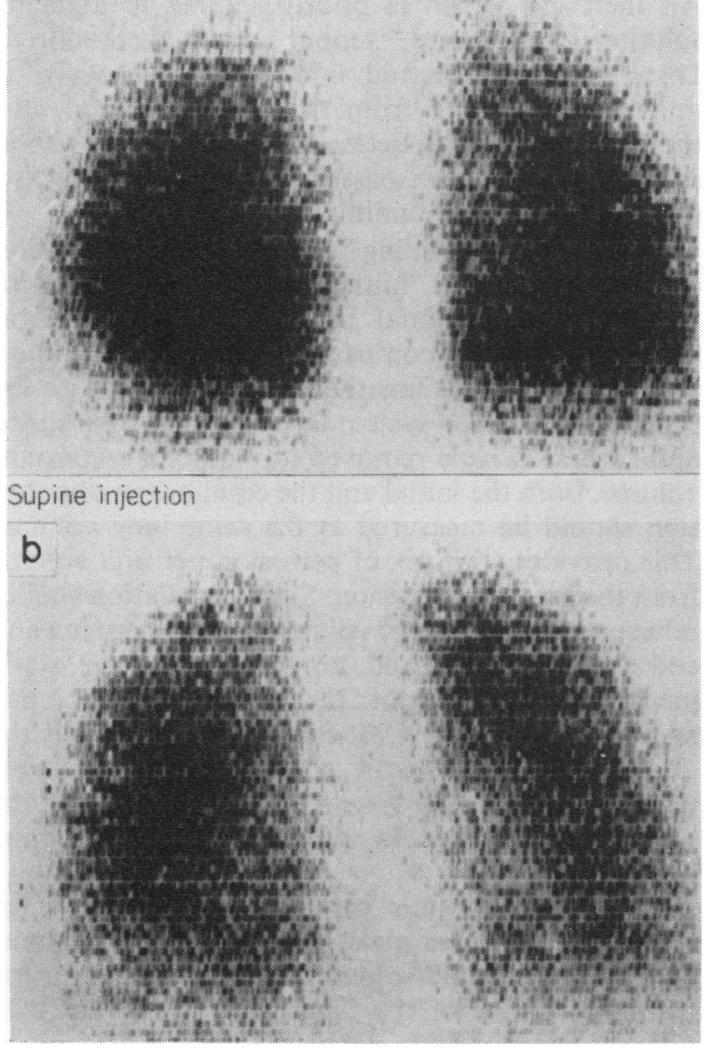

Fig. 2. Influence of gravity on distribution of macroaggregates. (a) Patient erect during injection. (b) Patient supine during injection. Evidently, particle distribution is more uniform in (b). imaging. Similarly, the effects of acute or transient situations on pulmonary blood flow can be conveniently studied. An asthmatic patient can be injected with particles during an acute attack, then treated and when the dyspnoea is relieved, brought for imaging which will show the distribution of blood flow during the attack.

The introduction of newer radionuclides with halflives of a few hours and lack of significant particulate or beta-like emission allows administration of larger amounts of activity, yielding higher count rates, better information density, shorter examination time, and a lower radiation dose than with ${ }^{131}$ iodine. Table 1 lists the properties of these newer radionuclides, ${ }^{99} \mathrm{~m}$ technetium and ${ }^{113} \mathrm{~m}$ indium as well as the more established ${ }^{131}$ iodine, which have been used to label a variety of particulate substances. Originally, metabolizable aggregates of albumin were used. Recently, albumin microspheres have been introduced. These can be sorted prior to labelling to insure greater uniformity and a narrow range of particle sizes. They can be stored conveniently in dried form (Rhodes et al., 1969). Other lung scanning agents employ flocculations of hydrous iron oxide made in sizes appropriate for capillary blockage (Goodwin, Stern \& Wagner, 1968; Davis, 1970).

In spite of the fact that one creates temporary blockage of a fraction of the pulmonary circulation the particulate scanning technique has a wide margin of safety. The large number of capillaries normally present exceeds the number of injected particles by a factor of about 1000 (Taplin et al., 1964). Further, there is a peculiar 'catch-trap' arrangement of the pulmonary microcirculation such that vessels feeding the capillary bed emerge at right-angles to the terminal pulmonary arterioles. The result is that occlusion of a terminal pulmonary distal to these branches does not block all or even most of the capillaries fed by that vessel (Knisely \& Knisely, 1954). The initial manifestation of toxicity from pulmonary arterial blockade is pulmonary hypertension without alteration of other parameters of pulmonary function, such as diffusing capacity (Brashear, Mishkin \& Reese, 1969). Even in patients with elevated pulmonary arterial pressure, however, no pressure changes occur following the administration of the particles (Johnson, 1971). Only in extreme instances of patients with cyanosis due to widespread obliteration of the pulmonary capillary bed should one hesitate to perform a lung scan. Adverse reactions have been rare, there being one reported fatality (Vincent, Goldberg \& Desilets, 1968) and one severe episode of dyspnoea followed by death in 2 days (Dworkin, Smith \& Bull, 1966). Both instances involved injection of an unusually large amount of albumin in a patient with a widespread occlusive process in the pulmonary vascular bed. Considering 
TABle 1. Properties of lung imaging agents

\begin{tabular}{|c|c|c|c|c|c|}
\hline Radionuclide & Tagged Substance & $\begin{array}{l}\text { Physical } \\
\text { half-life }\end{array}$ & $\begin{array}{l}\text { Biologic } \\
\text { half-life } \\
\text { in lung* }\end{array}$ & $\begin{array}{l}\text { Intravenous } \\
\text { imaging } \\
\text { dose }\end{array}$ & $\begin{array}{c}\text { Radiation } \\
\text { to lungs } \\
\text { (rads) }\end{array}$ \\
\hline 191Iodine & Macroaggregated albumin & 8 days & $6 \mathrm{hr}$ & $300 \mu \mathrm{Ci}$ & $1 \cdot 2-1 \cdot 8$ \\
\hline 118mIndium & Hydrous ferric oxide & $1.6 \mathrm{hr}$ & $4-12 \mathrm{hr}$ & $2 \mathrm{mCi}$ & $1 \cdot 5$ \\
\hline 9om Technetium & Macroaggregated albumin & $6 \mathrm{hr}$ & $4.6 \mathrm{hr}$ & $2 \mathrm{mCi}$ & $0 \cdot 8$ \\
\hline vomTechnetium & Hydrous ferric oxide & $6 \mathrm{hr}$ & $6-20 \mathrm{hr}$ & $2 \mathrm{mCi}$ & $1 \cdot 2$ \\
\hline 90mTechnetium & Albumin microspheres & $6 \mathrm{hr}$ & $14 \frac{1}{2} \mathrm{hr}$ & $2 \mathrm{mCi}$ & $0 \cdot 8$ \\
\hline 113mIndium & Albumin microspheres & $1.6 \mathrm{hr}$ & $14 \frac{1}{2} \mathrm{hr}$ & $2 \mathrm{mCi}$ & $1 \cdot 5$ \\
\hline${ }^{139}$ Xenon & Aqueous solution & $5 \cdot 2$ days & $30 \mathrm{sec}$ & $20 \mathrm{mCi}$ & $0 \cdot 05-0 \cdot 1$ \\
\hline
\end{tabular}

* Varies with particle size, number and fragility.

the critical clinical condition of many of the thousands of patients who have undergone lung scanning, the safety record is remarkable (Wagner, 1968).

In the presence of shunting to the systemic circulation consideration must be given to blockade of critical vessels in organs such as the brain. In routine lung scanning of patients with right to left intracardiac shunts no adverse occurrences have been reported and even intracarotid injection of the full scanning dose in primates and man produced no measurable effects (Kennady \& Taplin, 1965; Rosenthall, 1965). However, one group injecting low specific activity material in the carotid arteries observed sequelae in three out of twelve patients (King, Wood \& Morley, 1966). Another theoretical hazard, antigenicity of the albumin macroaggregates comprising the most widely used lung scanning agent, has not yet been demonstrable. An allergic reaction to stable iodide used to block thyroidal ${ }^{131}$ iodine uptake when this long-lived radionuclide label is used, may prove more likely than any haemodynamic alteration from the injection of particles (Bleik \& Bachynski, 1971).

Under normal circumstances, the blood buffets, erodes and dislodges the trapped radioactive particles within a few hours (Taplin et al., 1966), translocating them to the reticuloendothelial system chiefly in the liver and spleen. This process may be somewhat delayed in diseased areas of the lung. The short halftime in the lungs of 4-11 hr (DeLand, 1966) results in a radiation dose that is less than 2 rads to the lung (Furth et al., 1965), with the original beta emitting ${ }^{131}$ iodine label. This dose is of the same order of magnitude as that received during pulmonary angiography.

\section{Labelled gases}

Radioactive gases provide a sensitive physiologic means of assessing and comparing regional pulmonary blood flow and ventilation, employing either fixed probes (Ball et al., 1962) or imaging devices (Loken, 1971). Gamma emitting radionuclides of the physiological gases carbon monoxide, oxygen or nitrogen are cyclotron-produced (West and Dollery,
1960). Since these nuclides have half-lives of the ordes of a few minutes, they are available only at centres with access to a cyclotron.

${ }^{133}$ Xenon has a convenient 5-day half-life and gamma emission suitable for detection (Bates, Ball \& Bryan, 1964). Newer radio-isotopes of xenon, notablw ${ }^{135}$ xenon and ${ }^{127}$ xenon with more energetic gamma emission and more useful photons per $\mathrm{mCi}$ have recently become available (Newhouse et al., 1968g An inert gas which is poorly soluble in aqueous. solutions and blood, xenon is not metabolized Dissolved in saline and injected intravenously, immediately evolves from the capillary blood into the adjacent alveoli. Better than $90 \%$ of the gag is removed during each passage through the lung?si that recirculation is minimal.

During breath-holding after intravenous injectîto of dissolved xenon, initial alveolar distribution of xenon reflects regional pulmonary arterial bloo flow. This can be compared with the distribution after the patient has breathed to equilibrium with the ${ }^{133}$ xenon in a closed system to which oxygen is adde and carbon dioxide removed to maintain a constan volume. Both the initial and the equilibrium distribution should be measured at the same lung volume This provides an index of perfusion per unit volume from the injection of xenon. Single inhalation studies reflect regional ratios of volume at the beginning and end of inspiration and are determined by stat mechanical factors rather than dynamic factors such as airway resistance (Milic-Emili, 1972). Using the tidal volume ratio and comparing it to coun obtained after closed system equilibrium at end tida volume, one can obtain an expression of ventilatiofs per unit volume.

Use of xenon thus provides a direct althoug somewhat complex means of comparing region $\leftrightarrow 4$ ventilation per unit volume with regional perfusio per unit volume of the lung (Ball et al., 1962). order to assess poorly ventilated areas which xenof might not reach during a single breath, the rate of washout after breathing xenon to equilibrium in closed system for 10 min (Bryan et al., 1964) or the time taken in a particular region during wash-in 


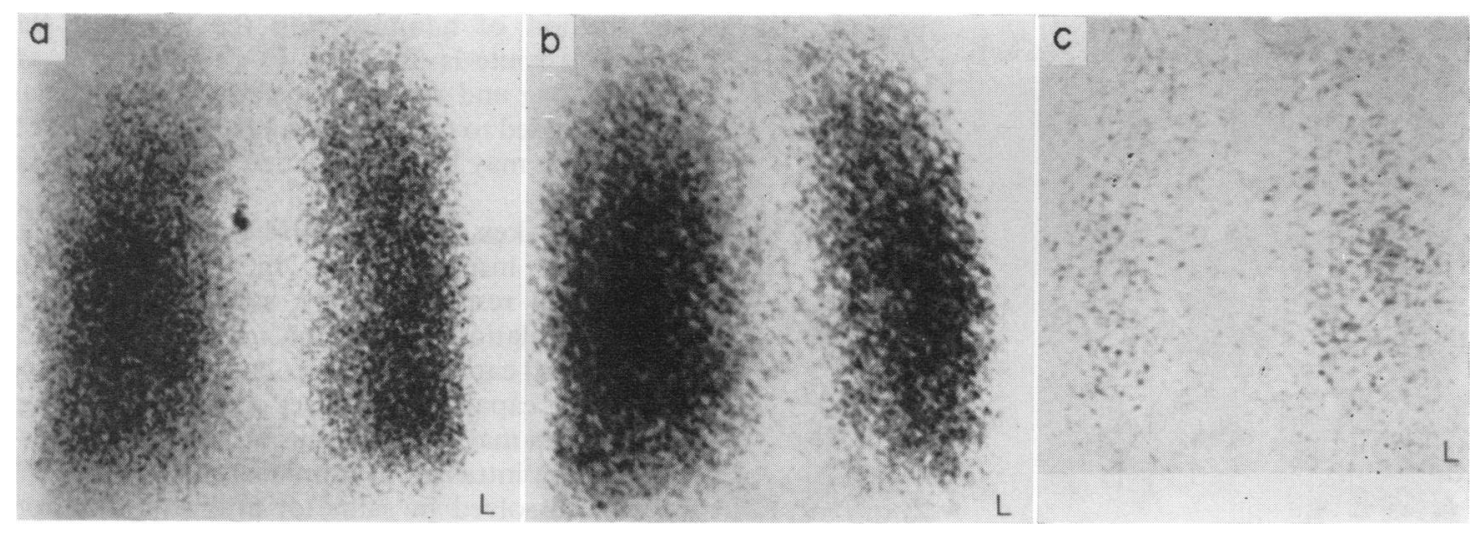

FIG. 3. Distribution of radioxenon-133 in the lungs, (a) after single inhalation of the gas, (b) after 'first pass' circulation of intravenously administered ${ }^{133}$ Xe dissolved in saline, (c) and near end of normal washout.

achieve $90 \%$ of the count rate at equilibrium (Bentivoglio et al., 1963) may be used as an index of regional ventilation. The scintillation camera allows visual estimation of regional ventilation : perfusion ratios adequate for routine clinical work (Loken, 1971; Mishkin, Brashear \& Reese, 1970) and can provide data that are readily quantitated (Fig. 3) (Burdine et al., 1969).

\section{Technical considerations Instrumentation}

In most laboratories either a rectilinear scanner or a scintillation camera is used to map the distribution of activity in the lungs. The rectilinear scanner views small areas incrementally while the camera views large areas at one time. Each has advantages and disadvantages for lung imaging (Gottschalk et al., 1971). Both devices have resolution that is limited in depth so that only half or less of the lung is seen from any given position, with overlying activity tending to obscure deep lesions. Lesions in the posterior region of the lung will not be seen on the anterior view and lesions adjacent to the mediastinum will usually not appear on the lateral view. One of the advantages of lung scanning is that multiple views may be obtained without additional radiation to the patient. In practice the number of views is limited by the patient's ability to co-operate and the time available for performing the study. In view of the limitation of the depth of view of the instruments, a minimum of four views, including anterior, posterior and both lateral aspects, proves essential for adequately surveying the lungs (Sasahara, Belko \& Simpson, 1967a; Surprenant, 1967; Mishkin, 1968; Mack et al., 1969).

Usually the output of the camera is a minified image on Polaroid(R) film or 35 or $70 \mathrm{~mm}$ trans- parencies, whereas the image from a rectilinear scanner is life-size. Neither output is a true constraint of the imaging system, and may be readily altered. The head of the camera may be moved to any height or angle allowing examination of patients, such as those confined to bed, in traction or with severe orthopnoea, who cannot be examined on the rectilinear scanner. Furthermore, the rapid response of the camera to a large field of view allows performance of dynamic physiologic studies such as serial inhalation and rebreathing with xenon, which are impossible to do with the rectilinear scanner.

Neither instrument has a clear-cut advantage of resolution. Time required to expose four views of the lungs is approximately the same for a dual-headed scanner and for the scintillation camera. Rectilinear scanners have a tomographic effect which becomes increasingly exaggerated with increasing size of the crystal. Cameras do not; their response is subject to the inverse square law, so that greatest resolution is given to superficial structures. The scanner provides uniform response for the whole field viewed and can place both lung images on a single film, whereas the camera may have non-uniform field response and result in a mildly distorted image if a diverging collimator is used to capture the image of both lungs on a single scintiphotograph.

Dual-headed scanners show differences between the superior and dependent lungs on the lateral views due in part to anatomic and physiologic changes, with the cardiac mass intruding on the dependent lung and the dependent hemidiaphragm being high with increased motion, the superior hemidiaphragm being down and splinted. The effect of gravity in shifting free pleural fluid may also become apparent on the lateral views performed with a dual-headed rectilinear scanner. When the involved lung is 


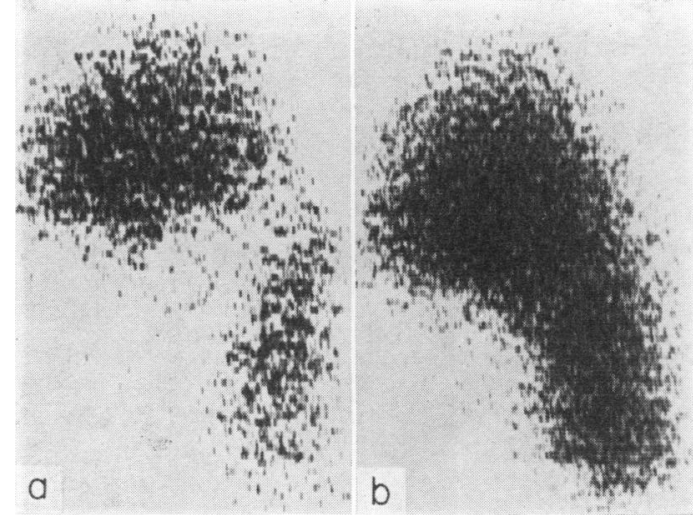

Fig. 4. (a) 'Fissure sign' due to pleural effusion. (b) Left lateral scan shows complete clearing of the finding due to resolution of the effusion in the 8-week interval between examinations.

dependent, fluid moves to the lateral chest wall and if sufficient in amount rises into the fissures and spreads the lobes apart. This gap is known as the 'fissure sign' (Fig. 4). It disappears when the patient lies on the opposite side, allowing the fluid to drain to the mediastinum and the lobes to come back into apposition. Usually the probe over the upper lung is further from the body than the probe beneath the patient, resulting in some distortion and a plane cut nearer the surface than obtained with the bottom probe. For all the reasons listed above, cameras and scanners each have their devotees, but as far as routine lung scanning is concerned neither has a decided advantage over the other at present.

\section{Ventilation studies}

These can be simply done with a gamma camera and a few accessories. The minimum requirement is气̊ some method of administering the xenon if thez intravenous route is not used. For this purpose an anesthesia bag and mask is satisfactory. A Douglas. bag may be used to trap the patient's breath for 4 or $5 \Rightarrow$ min. The bag may then be emptied outside or into $a^{?}$ vented hood.

A picture taken during breath-holding at end tida产 volume after inspiring $20-40 \mathrm{mCi}$ of a ${ }^{133} \mathrm{Xe}$-air mixture from residual volume suffices to estimate® regional ventilation. Inspiration may be from functional residual capacity to either end-tidal volume orto total lung capacity. To detect occult air trapping;serial pictures may be taken during washout follow $\vec{\tau}$ ing either the intravenous administration of $20 \mathrm{mC}$ ? of xenon dissolved in saline or after equilibrationo with xenon gas in a closed system. The normal wash 3 out half-time is about $30 \mathrm{sec}$, so that activity whichto persists after 4 min of washout should be regarded asion evidence of air trapping.

\section{Injection of radioactive particles}

This is best performed over several deep respira- tions with the patient supine. The supine position insures uniform distribution of blood flow from apex $=$ to base. Marked clumping or aggregation of particles prior to injection, particularly in conjunction witho small blood clots in the syringe, invalidates assumption of uniform particle concentration in blood received by the lung. These iatrogenic emboli produce focal areas of increased activity and require longer time for breakdown and removal (Fig. 5) (Duffy, DeNardo \& Abington, 1968). When informa tion concerning left atrial pressure is sought, injection should be made with the patient upright in order tợ detect a shift in the normal apex to base gradient of activity that occurs with elevation of left atria pressure (Friedman \& Braunwald, 1966).

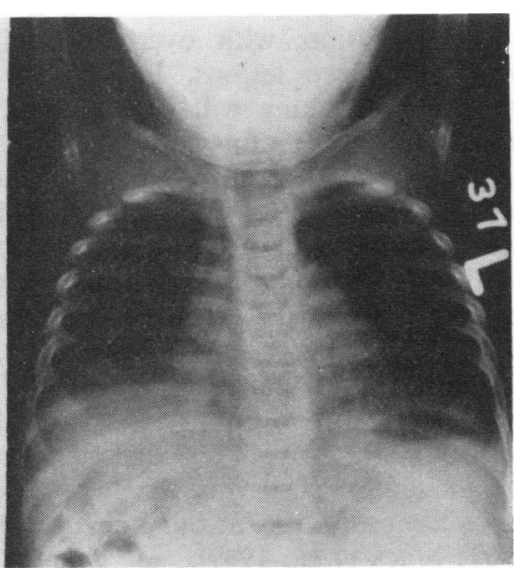

FIG. 5. The 'hot spot' at the right lung base is an artefact due to clumping of macroaggregates before injection. S, sternal notch; $X$, xiphoid. 
Imaging is begun immediately after injection. When the rectilinear scanner is used, care should be taken to make the response of film blackening linear in relation to activity. If contrast enhancement is used, that is, exaggeration of small differences in count rate by large differences in film density, the data will be distorted and potentially misleading. The time exposure of the scintillation camera may be terminated after a preselected time or after obtaining a preselected number of counts. Using the latter method may lead to erroneous conclusions in interpreting the lateral views, since overall diminution of activity will be compensated for by increased exposure time.

Every examination must be accompanied by a current chest roentgenogram. Perfusion deficits on the scan lack aetiological specificity because regional ventilatory changes affect regional perfusion. The film is essential to provide a crude measure of regional ventilation and thus assist in evaluating a perfusion deficit. The chest roentgenogram should be taken just prior to the scan and used in deciding whether or not a scan will be helpful. For example, if large bilateral infiltrates are present, the probability that the scan will yield useful information is quite low. On the other hand, if the chest roentgenogram is normal and the patient is suspected of having obstructive lung disease as well as embolism, it may be worthwhile doing a ventilation study with xenon.

\section{Physiologic factors in pulmonary embolism}

Efficient gas exchange in the lung requires matching of alveolar ventilation with pulmonary arterial blood flow since exchange cannot occur unless ventilated alveoli receive the appropriate amount of mixed blood. Regional differences in pleural pressure, gravity and other mechanical factors result in a gradient of ventilation in the upright lung that increases from apex to base. Blood flow also increases in the more dependent portions of the lungs, but more rapidly than ventilation. The ventilation : perfusion ratio therefore decreases from apex to base (West, 1970). Appropriate compensatory mechanisms exist to approximate a normal relation of ventilation and perfusion in the face of alteration of either.

Interpretation of the lung scan depends upon understanding the response of the pulmonary circulation to abnormal ventilation and to changes in the $\mathrm{pH}$ and gas content of the blood. Alveolar hypoxia is a potent cause of pulmonary vasoconstriction (Arborelius, 1969). It appears to exert a greater effect on lower zone than upper zone vessels (Dawson, 1969) and directly depends on the hydrogen ion concentration of the blood (Lloyd, 1966). Most causes of decreased ventilation produce regional alveolar hypoxia and result in decreased perfusion owing to redistribution of blood flow away from the hypoventilated area (Lopez-Majano, 1970). Elevated alveolar $\mathrm{CO}_{2}$ tension also produces pulmonary vasoconstriction, a response which may be blunted in patients with chronic lung disease (Twining et al., 1968).

Pulmonary perfusion is altered by blood $\mathrm{pH}$ and gas tensions. Increased blood hydrogen ion concentration and pulmonary precapillary hypoxemia cause pulmonary vasoconstriction, elevation of pulmonary arterial pressure and increased pulmonary vascular resistance (Enson et al., 1964; Bergofsky et al., 1963). A similar but less efficient mechanism to reduce ventilation when perfusion diminishes depends upon the bronchodilator effect of $\mathrm{CO}_{2}$. Mixed venous blood supplies $\mathrm{CO}_{2}$ to maintain alveolar $\mathrm{CO}_{2}$ tension. Decreased alveolar $\mathrm{CO}_{2}$ tension resulting from pulmonary artery occlusion is followed by bronchoconstriction and hypoventilation (Swenson, Finley \& Guzman, 1961; Allgood et al., 1968).

\section{Problems in clinical recognition of pulmonary embolism}

It is axiomatic that unless suspected a diagnosis will not be made. The manifestations of even massive acute pulmonary embolism are deceptively nonspecific (Wenger, Stein \& Willis, 1972). Of the traditionally taught signs and symptoms, only dyspnoea occurs in the vast majority of cases (Sasahara et al., 1967c). While chest discomfort is common, pleuritic pain is not and haemoptysis is infrequent. The most commonly observed signs include tachypnoea in the vast majority and, less frequently, tachycardia. Pulmonary embolism often occurs in the presence of underlying cardiopulmonary disease, including arteriosclerotic coronary artery disease, rheumatic valve disease, congestive heart failure, thrombophlebitis and chronic obstructive lung disease (Wenger et al., 1972; Sasahara et al., 1967c; Hampton \& Castleman, 1940). Immobility and venous stasis accompanying surgery, childbirth, blunt trauma or fractures involving the hips and lower extremities set the stage for embolism, as do certain neoplasms. Even previously healthy persons with occupations which predispose to venous stasis in the lower extremities are at risk, as are women taking anovulatory agents.

Of the routine laboratory studies, only arterial hypoxaemia is common to almost all patients with embolism (McIntye \& Sasahara, 1971a). In fact, if the arterial partial pressure of oxygen is normal in a patient breathing room air, a lung scan will probably be normal since the scan is no more sensitive than the $\mathrm{Po}_{2}$ (Szucs et al., 1971). In the majority of cases hypoxaemia cannot be corrected by administering $100 \%$ oxygen, suggesting that significant venous admixture contributes to hypoxaemia during the 
acute phase. Other sources of hypoxaemia in pulmonary embolism which do respond to the administration of $100 \%$ oxygen include ventilation : perfusion ratio non-homogeneity, obliteration of the pulmonary vascular bed producing decreased diffusing capacity and relative alveolar hypoventilation (Kafer, 1969; Wilson et al., 1971). Tachypnoea results in increased excretion of $\mathrm{CO}_{2}$ so that the hypoxaemia is generally accompanied by a low $\mathrm{PCO}_{2}$. Increased alveolar dead space in pulmonary embolism due to continued ventilation of nonperfused areas of the lung leads to a lowering of the alveolar $\mathrm{PCO}_{2}$ as compared with the arterial $\mathbf{P C O}_{2}$ (Robin et al., 1960). Bronchoconstriction produced by hypocapnoea partially corrects this discrepancy between arterial and alveolar $\mathrm{PCO}_{2}$ which is also found in other diseases with increased dead space, principally emphysema (Robin et al., 1959).

The hallmark of pulmonary embolism, a high ventilation:perfusion ratio, results from regional ischaemia with intact or slightly diminished ventilation (Bass, Heckscher \& Anthonisen, 1967). This can be demonstrated by comparing the image obtained

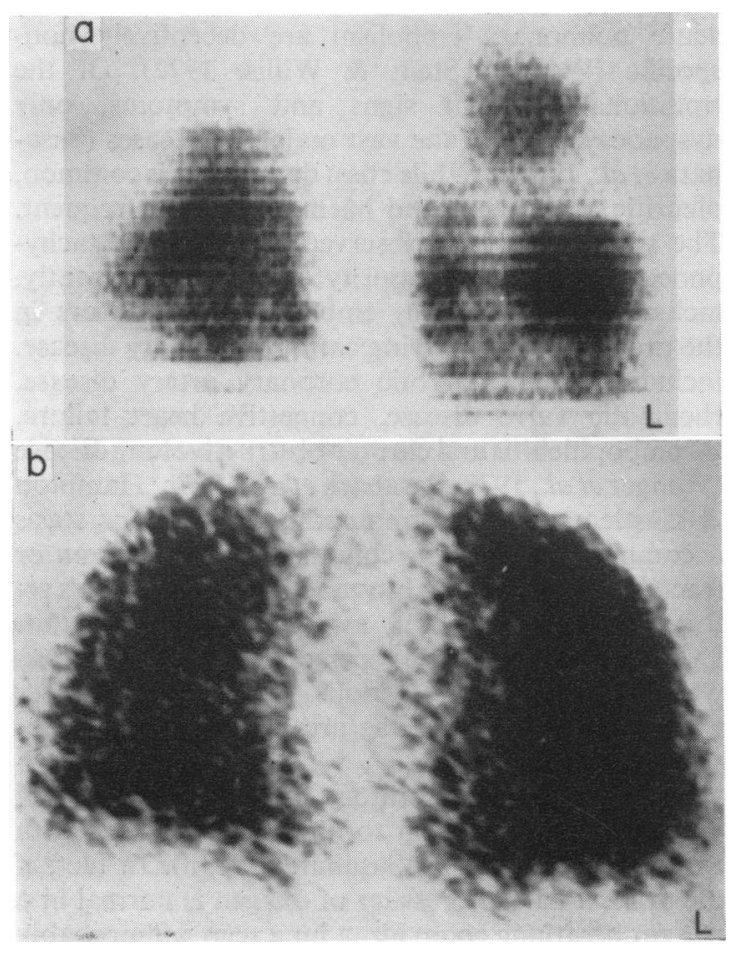

FIG. 6. Pulmonary embolism. (a) Perfusion scan shows multiple areas of ischemia. (b) Ventilation image using ${ }^{133} \mathrm{Xe}$ shows normal aeration of both lungs. This set of findings is considered pathognomonic of pulmonary embolism. following a single inspiration of ${ }^{133}$ xenon with aै perfusion study performed with radioactive particles (Fig. 6). On the other hand, chronic obstructive lung disease is associated with areas having a low ventila 4 . tion:perfusion ratio, the ischaemia often resulting from alveolar hypoxia. In this case the study with? radioactive gas will show ventilation defects whiche may or may not match the perfusion deficits (Fig. 7) (DeNardo et al., 1970).

Excellent reviews emphasize the lack of sensitivity $\mathbb{D}$ and specificity for pulmonary embolism of all otherw ancillary studies, including measurements of serumlactic dehydrogenase, combinations of enzyme measurements such as serum lactic dehydrogenase $\vec{\omega}$ serum glutamic oxalacetic transaminase and serume bilirubin, electrocardiography, routine chest roente genography and pulmonary function studies (Wengere et al., 1972; Sasahara et al., 1967c). The latter arछ helpful in separating patients with pulmonary embolir ism alone from those with embolism and chronic lungw disease. Pulmonary function studies also provide ${ }_{0} \mathrm{O}$ simple means of following the disease process (Bass, Banas \& Dalen, 1970).

\section{Lung scan compared with arteriography}

The lung scan provides the most sensitive test for pulmonary embolism, being rivalled only by measures $\overrightarrow{0}$ ment of arterial $\mathrm{Po}_{2}$. Short of necropsy and surgicar proof, arteriography remains the most specific meagis: of demonstrating embolism (Simon \& Sasaham 1965; Bookstein, 1970). Although unsuitable as के screening procedure, owing to its specialized naturê and potential morbidity, arteriography gives superbly detailed display of major vascular anatomy The scan, on the other hand, evaluates perfusion a? the arteriolo-capillary level. It is not surprising therefore, that the two methods occasionally yiele different information. In general, arteriography is better able to delineate proximal occlusions involving major vessels and the scan the smaller, peripherab emboli. When less than $40 \%$ of the total lung is involved, the scan may provide the best estimate of the extent of involvement, whereas in more severe forms of embolism the arteriogram may yield the best information (McIntyre \& Sasahara, 1971b). This discrepancy may reflect partial occlusion of majov vessels (Moser et al., 1969) or recanalization of majo proximal vessels permitting relatively uniform flowo into the distal capillary bed (Fig. 8).

Many investigators have compared arteriography and scanning in pulmonary embolism (Wagner et al. 1964; Fred et al., 1966; Moser et al., 1966; Hildner \& Ormond, 1967; Bell et al., 1968; Freeman et al., 1968 $\frac{6}{\bar{E}}$ McIntyre \& Sasahara, 1971b; Gilday, Poulouse $\$$ DeLand, 1972; Wellman et al., 1973). In these combined series were 167 patients having pulmonary arteriograms positive for embolism, 157 of whong 


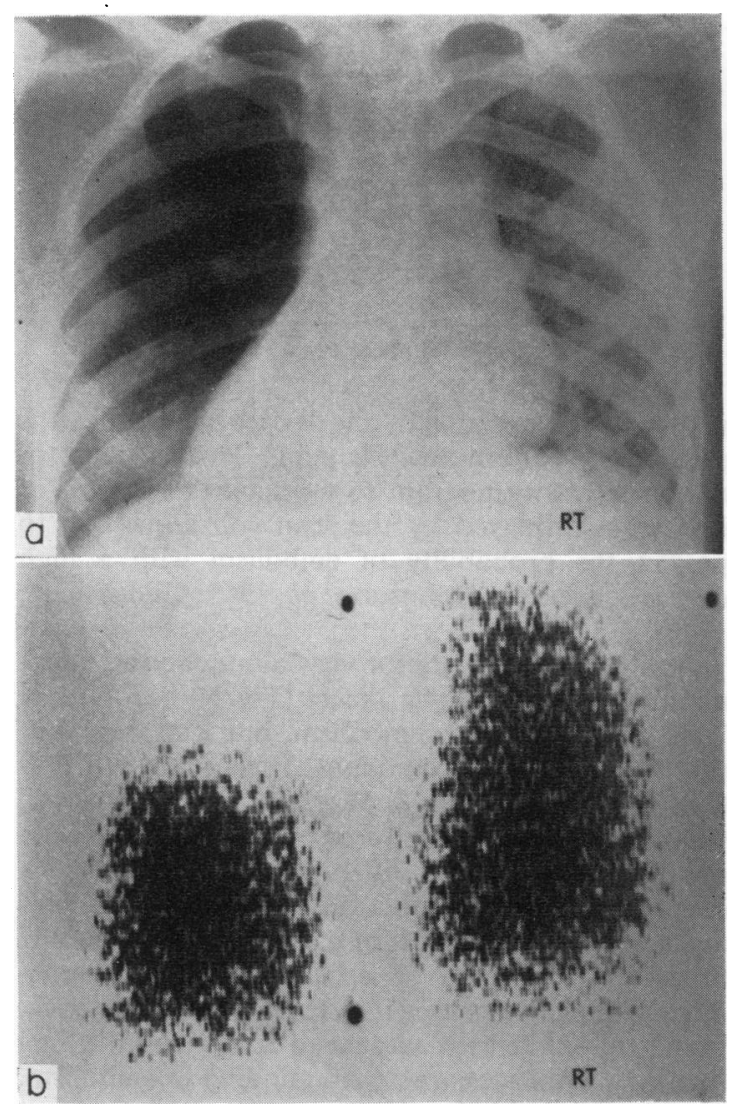

Fig. 7. Obstructive lobar emphysema. Reversed chest film (a) shows an over-inflated left upper lobe that is totally ischemic on the perfusion scan (b). Closedsystem ventilation study using ${ }^{183} \mathrm{Xe}$ (c-e). The abnormal lobe (arrow) exhibits initial non-entry of the radioactive gas (c). 6 min later (d) its ${ }^{133} \mathrm{Xe}$ content approaches that of normal lung. Inefficient washout is evident by lobar retention of ${ }^{12} \mathrm{Xe} 42 \mathrm{sec}$ (d) and $150 \mathrm{sec}$ (e) after start of room air breathing.

also had positive scans. The ten scan 'failures' occurred in two earlier series technically inadequate by current standards. From these data, especially the major prospective study by Wellman et al. (1973) (Table 2), the conclusion may be drawn that a normal scan effectively excludes the possibility of arteriographically demonstrable emboli, provided that examination comprises four technically satisfactory views. The converse is of course not true: the positive lung scan is not proof of embolism.

\section{Scan findings in pulmonary embolism}

Embolism results in many different syndromes and, not unexpectedly, no one scan pattern is specific. Attempts to characterize the scan appearance of embolism yield statistical priorities of patterns, but

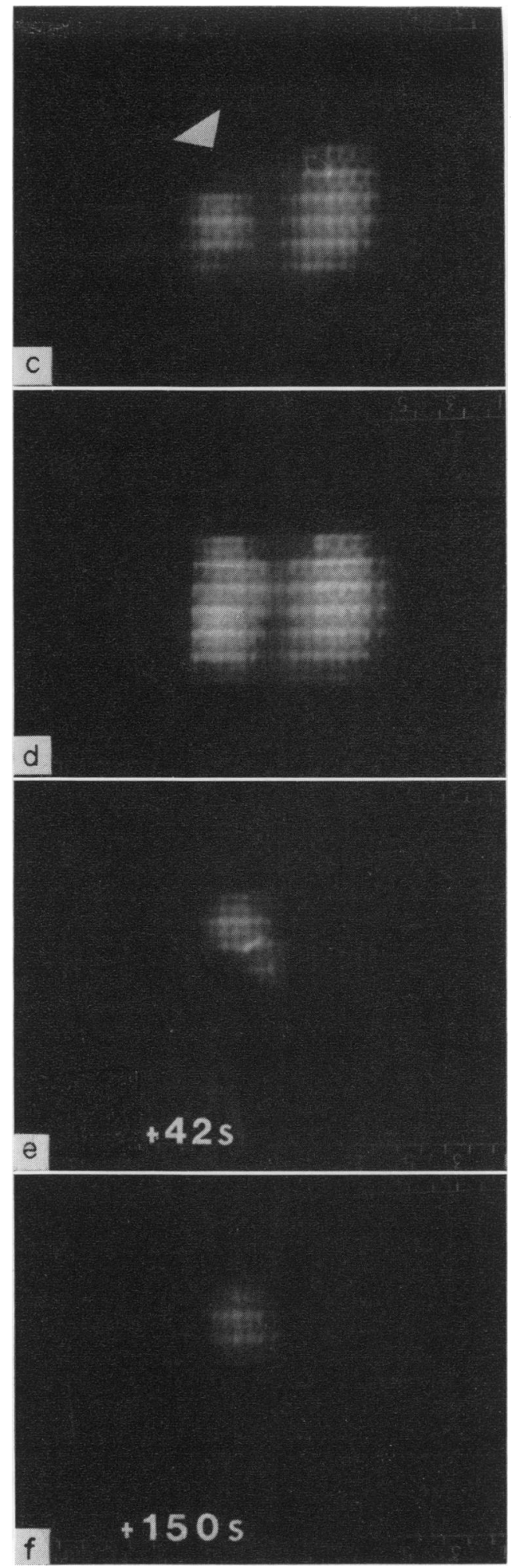



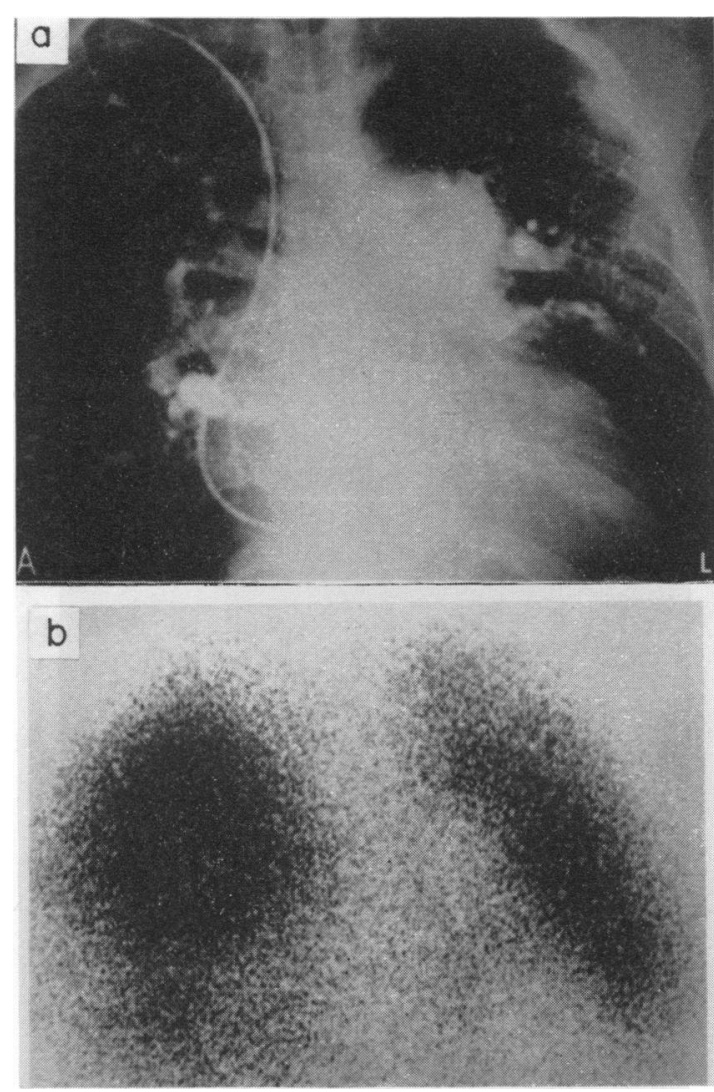

FIG. 8. Complementary nature of scan and angiography. The arteriogram (a) shows occlusion of major vessels proximally; the scan (b) shows large peripheral perfusion deficits. The discrepancy results from incomplete occlusion of the proximal vessels, allowing particles to pass toward the periphery.
TABLE 2. Comparison of the scan and arteriogram in pulmonary embolism*

\begin{tabular}{llc}
\hline Arteriogram & Scan & No. of studies \\
\hline Positive & Negative & 0 \\
Positive & Positive & 24 \\
Negative & Negative & 8 \\
Negative & Positive & 28 \\
\hline Total & & 60 \\
\hline
\end{tabular}

* From Wellman et al. (1973).

no clear-cut separation of one disease from another is $\overrightarrow{0}$ possible by pattern analysis alone. However, use of $\vec{\overrightarrow{ }}$ the chest roentgenogram to evaluate the pattern of $\omega_{\sigma}$ ischaemia displayed by the scan will allow one to predict the probability of embolism with a high 3 degree of accuracy (Johnson et al., 1969; Gilday et al., 1972).

Analysis of the posterior view alone showed that a midlung field crescentic defect (Fig. 9) occurred in $72 \%$ of patients with embolism, but with only half $\stackrel{\infty}{0}$ that frequency in chronic lung disease and tubercu- $ᄋ$ losis (Poulouse, Reba \& Wagner, 1968). However, what appears to be a small crescentic area of ischaemia $\measuredangle$ on the posterior view often can be seen to be a complete segmental defect on the lateral view. This $\vec{\omega}$ again emphasizes the role of the lateral view, not ong $\omega$ in detecting an area of ischaemia, but in charas terizing and quantitating it. A focal area of ischaemi that is, a well-defined absence of activity on the lung scan, is the most characteristic finding in embolism. 을 The pattern of involvement corresponds most $\stackrel{\otimes}{\varnothing}$ frequently to a lung segment, and in order of $\unrhd$ decreasing frequency to a lobe, an entire lung (almost $\overrightarrow{\overrightarrow{0}}$ always accompanied by a focal defect in the other 3 lung, as seen in Fig. 10), or a non-segmental portion
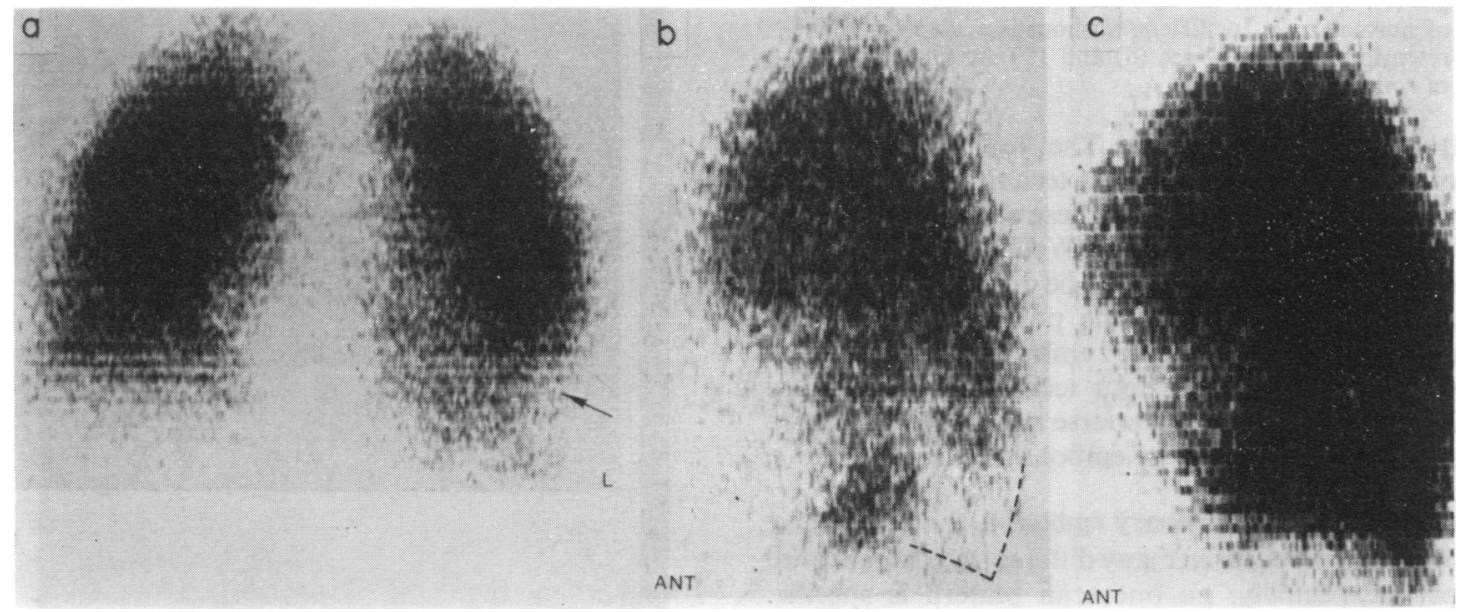

FIG. 9. The posterior view (a) in a patient with pulmonary embolism shows a crescent-shaped peripheral defect, which the lateral view (b) demonstrates to be segmental. A repeat study (c) shows return to normal 1 week later. 


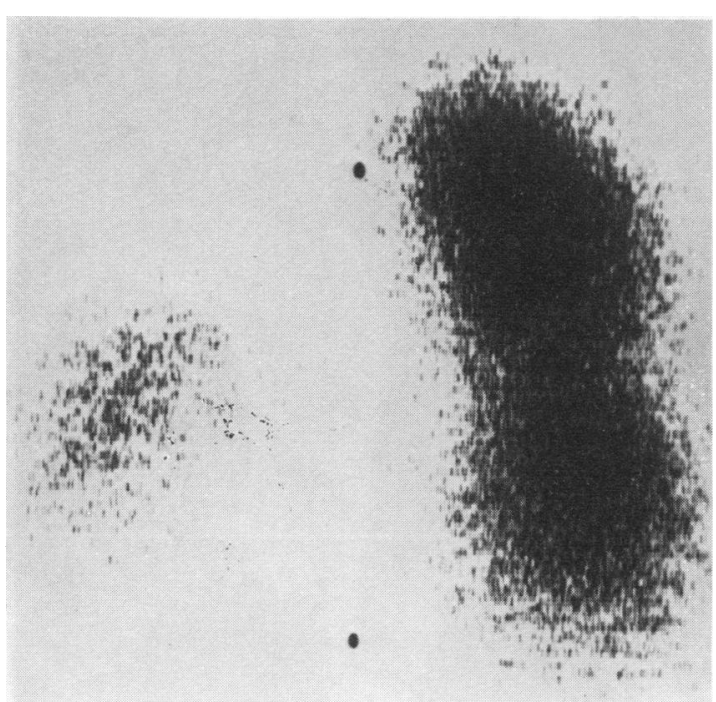

FIG. 10. Scan in massive right-sided pulmonary embolism with a smaller peripheral embolism on the left. The chest film was clear. This patient expired within $24 \mathrm{hr}$.

of the lung (Gilday \& James, 1972). A diffuse or patchy pattern of ischaemia is rare as a scan manifestation of embolism.
The vast majority of emboli are bilateral and multiple (Smith et al., 1965) and occur at the periphery of the lung. Most frequently the lower lobes are affected (Wellman et al., 1973), right more than left; then in order of decreasing frequency the left upper lobe, the right middle lobe and the right upper lobe. The scan pattern reflects the pathologic anatomy. Scan findings which suggest a high probability of pulmonary embolism thus include focal defects which are multiple and often bilateral, occur at the lung periphery, are convex toward the hilum and, while appearing crescentic on the posterior view, usually can be seen to involve a segment, subsequent or entire lobe on the lateral view.

Recurrent embolism is common. A frequent pattern encountered in this situation is a combination of segmental defects with visualization of the lung fissures (Fig. 11). Fragmentation and lysis of previous emboli, which has been shown to occur experimentally (Moser et al., 1969), presumably result in release of peripheral microemboli. These in turn reduce the perfused lung volume, unperfused lung outlining the entire periphery. This can best be demonstrated in the area of the fissures where non. perfused lung is in contact with adjacent perfused lung. Nevertheless, visualization of the fissure on the lateral lung scan is a non-specific finding (James et al., 1971). As noted above, when it is due to pleural

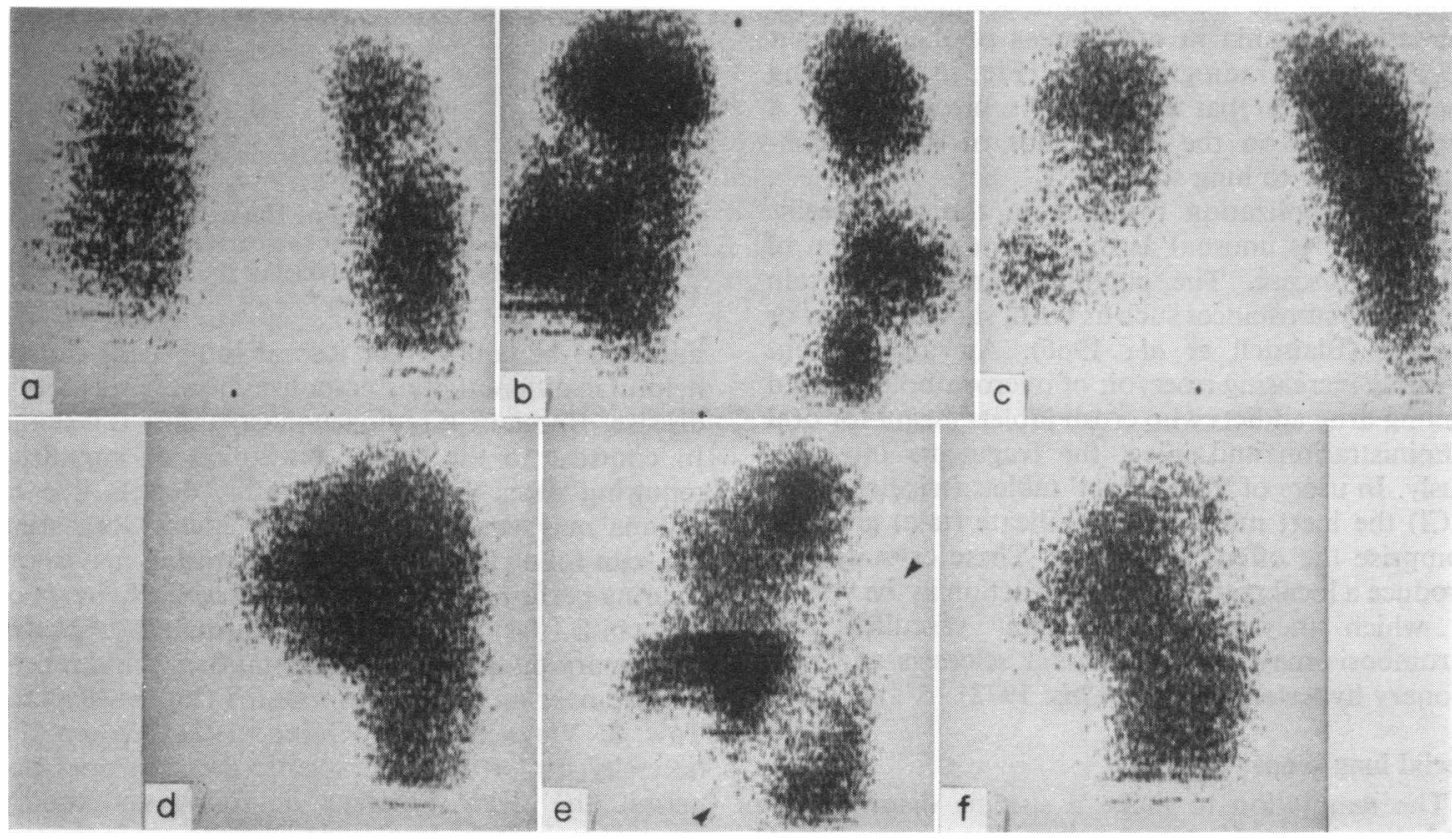

Fig. 11. Recurrent embolization, posterior $(a, b, c)$ and left lateral $(d, e, f)$ views. Initial scan (a and d) shows perfusion deficits confined to the right lung. 6 weeks later ( $b$ and $e$ ) the left lung shows multiple deficits and a 'fissure sign' (arrowed). 18 days later ( $c$ and $f$ ) significant but incomplete resolution has occurred. 
fluid, the disappearance of the fissure sign when the dependent lung is placed uppermost is a valuable differential feature (Gize, Dizon \& Mishkin, 1971).

Massive pulmonary embolism involving $50 \%$ or more of the lung presents a striking scan appearance (Fig. 10). Most often both lungs are involved. The accompanying chest film may show increased lucency in the ischaemic areas due to pulmonary oligaemia. Total unilateral pulmonary ischaemia is an uncommon finding and is observed less often in pulmonary embolism than in bronchogenic carcinoma or other mass lesions involving the hilum of the lung. The presence of a defect in the other lung, however, makes embolism more probable.

Pulmonary embolism is not often followed by infarction (Smith et al., 1965). Usually incomplete infarction ensues and results in only transient radiographic abnormalities (Hampton \& Castleman, 1940). Complete infarction, which may require weeks or months to resolve, most frequently appears in patients with underlying cardiopulmonary abnormalities, such as congestive heart failure. Scanning seldom delineates the nature of a density seen on the chest film. Densities not due to infarct will rarely show normal perfusion (Fig. 12) or else ischaemia due to diminished ventilation. However, several features are of value in suspected infarction. In the initial stages, the area of ischaemia depicted by the scan is usually much larger than the density due to infarction on the roentgenogram. Scanning may also unmask ischaemia in other areas of the lung that appear normal radiographically (Fig. 13), increasing the probability that embolism is present. Thus a focal density on the film is not of itself a contraindication to lung scanning.

Microembolization resulting in the non-specific fissure sign is unusual as the only manifestation of embolic disease. The condition arises in certain clinical circumstances such as burn, shock, surgery or trauma (Blaisdell et al., 1966). An unusual but possibly increasing reservoir of microemboli is found among drug addicts who crush tablets meant for oral administration and inject the fragments intravenously. In users of 'blue velvet' tablets (tripelenamine $\mathrm{HCl})$ the inert magnesium trisilicate (talc) granules comprise the offending emboli. These crystals also produce a local granulomatous reaction in the vessels in which they lodge. Resultant vasculitis and thrombosis may lead to vascular sclerosis and pulmonary hypertension (Hopkins, 1972).

\section{Serial lung scans}

The temptation to make a specific diagnosis of embolism is strong when the chest film is normal and the lung scan shows several clear-cut focal defects. It should be resisted since not only embolism, but acute asthma, bronchitis or occult obstructive lung disease

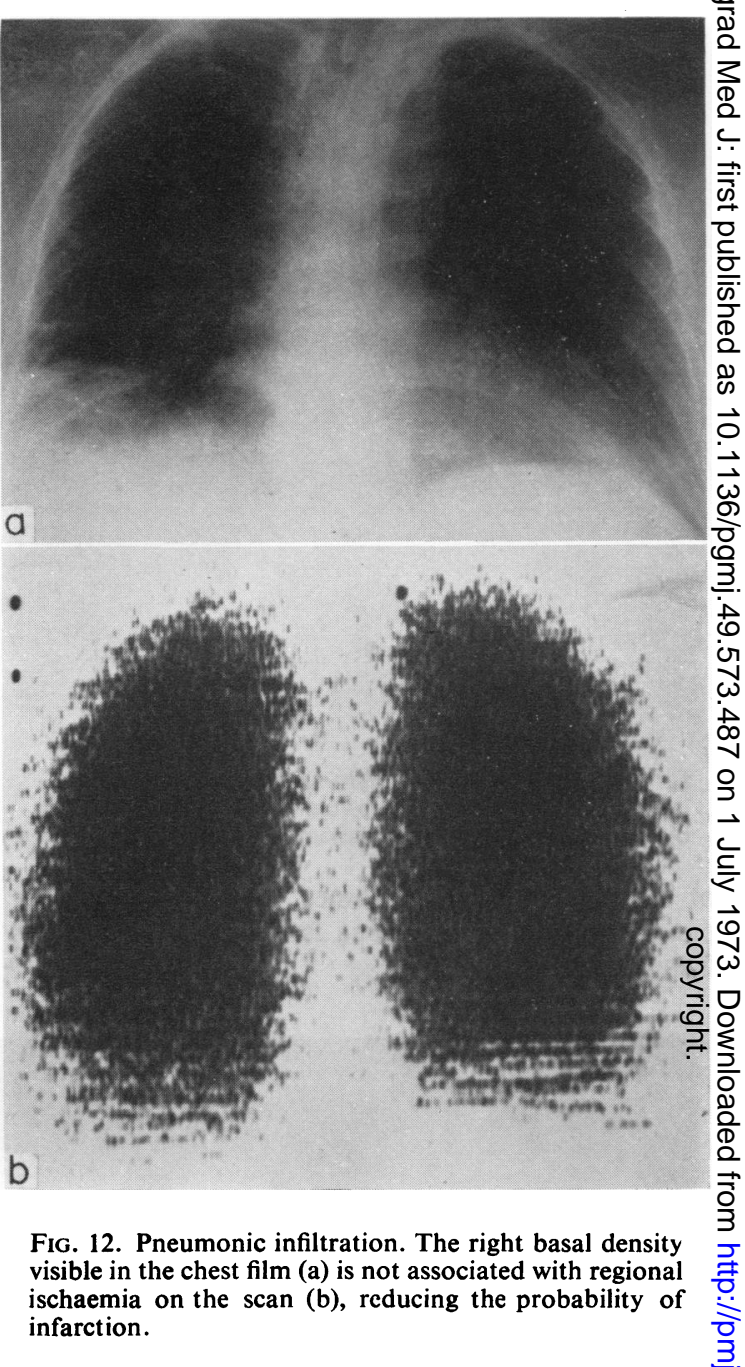

must also be considered. Repeat lung scans can be helpful in differentiating embolism from non-embolic 3 . disease, especially if radioxenon capability is lacking. $ᄋ$ In contrast to the slower resolution of embolism requiring days, weeks, or months, defects due to $\circ$ asthma may vanish within a few hours. Repeating the scan following oxygen administration may show clearing perfusion in deficits related to the hypoxia of bronchitis. Ischaemia due to chronic obstructive $\sigma$ pulmonary disease tends to be stationary and repro- $N$ ducible over an interval of months (Lopez-Majano, $\underset{\omega}{\mathcal{N}}$ Tow \& Wagner, 1966; Quinn, 1971). When the o necessity for prompt therapeutic decision does not permit the delay inherent in follow-up studies, $\stackrel{\odot}{\Phi}$ imaging techniques employing ${ }^{133}$ xenon are indicated. $\stackrel{?}{?}$

Perhaps the most unique feature of serial scanning 0 in pulmonary embolism is the ability to characterize $\overline{0}$ the course of the disease and evaluate the results of $\frac{\mathbb{}}{\otimes}$ 


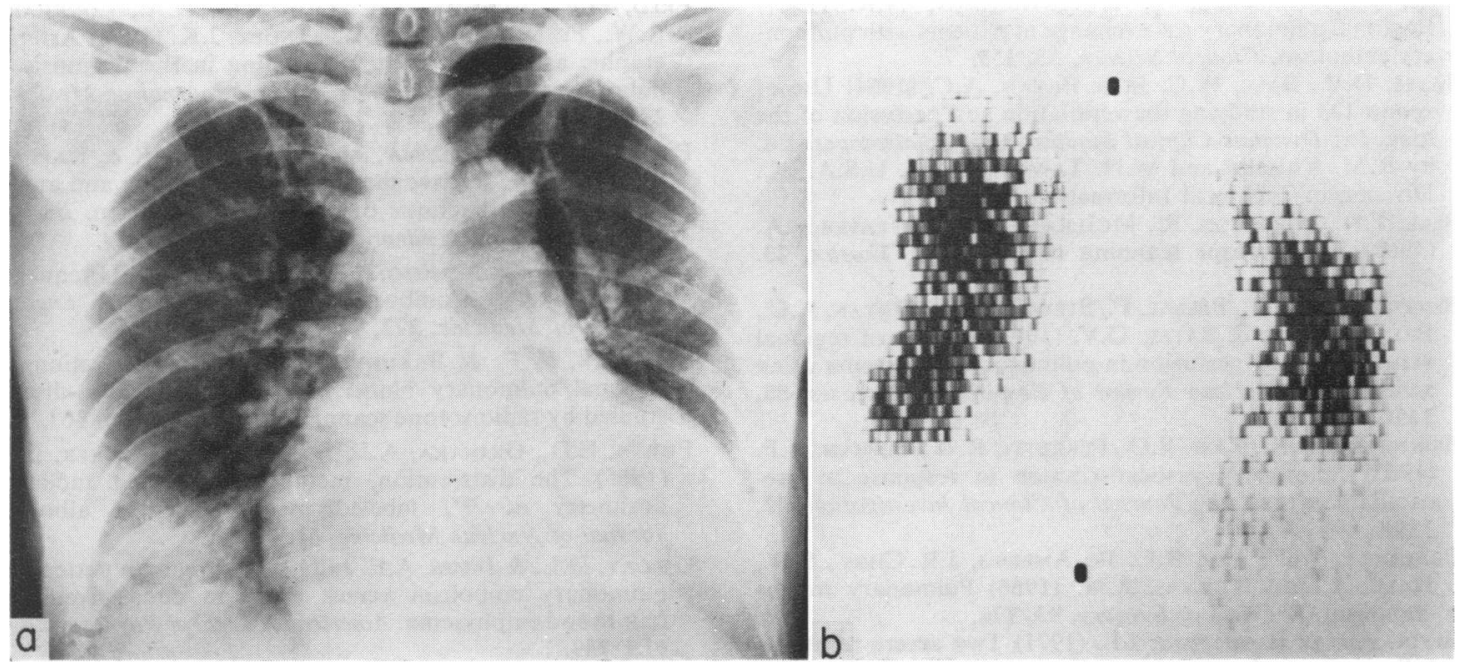

FIG. 13. Embolism complicated by infarction. The right basal density evident on the chest film (a) is smaller than the associated perfusion deficit shown on the scan (b). This finding of itself favours the diagnosis of pulmonary infarction at the right base. The probability is increased by the demonstration of other discrete perfusion deficits, consistent with uncomplicated emboli.

therapy. Scanning lends itself to quantitation by various methods (Lopez-Majano et al., 1964; Friedman \& Braunwald, 1966) and is reproducible (Lopez-Majano et al., 1967). A gross guide is to assign a loss of $5 \%$ of the total lung perfusion for every named segment completely involved and half that amount if the perfusion is only partially reduced. Shifting perfusion deficits are not uncommon (Fig. 11). Often one area resolves even as a new deficit appears, while the patient improves clinically. Thus one should not rely on the scan alone in arriving at a therapeutic decision, since shifting deficits do not necessarily imply new or recurrent emboli.

Although angiography has been used to show the resolution of large clots (Dalen et al., 1969) it is neither a simple nor a repetitive technique. From two series (Tow \& Wagner, 1967; Winebright, Gerdes \& Nelp, 1970) factors which affect the time course and degree of resolution have been found by serial scans to include the extent of initial involvement, the presence of underlying cardiovascular disease and the age of the patient. These data show that rapidity and completeness of resolution are greater with smaller degrees of initial perfusion deficit. Thus, the more the initial involvement, the longer the time required and the less complete the resolution of the initial perfusion deficit.

The majority of patients with more than a $30 \%$ initial deficit did not regain complete restoration of perfusion. Similarly, none of the patients of more than 60 years of age showed complete restoration of blood flow, while those between 40 and 60 years of age clearly required a longer time and had less complete resolution of ischaemia than patients less than 40 years of age. Only a small minority of patients with underlying heart disease had complete restoration of blood flow, and the time required for improvement of blood flow was prolonged compared with patients without cardiac disease. These residual defects may be misinterpreted as new emboli in the appropriate clinical setting. This error is prevented if the earlier episode was followed to its resolution endpoint by serial scanning. Only the use of serial scanning has made such data available as well as making possible the recent comparison of the thrombolytic effect of urokinase and heparin (Tow, Wagner \& Holmes, 1967; Sasahara et al., 1967b; Co-operative Study, 1970).

For the interested physician there are available comprehensive reviews of pulmonary imaging in diseases of the lungs (Mishkin \& Brashear, 1971; Gilson \& Smoak, 1971).

\section{References}

Allgood, R.J., Wolfe, W.G., Ebert, P.A. \& SAbiston, D.C., Jr. (1968) Effects of carbon dioxide on bronchoconstriction after pulmonary artery occlusion. American Journal of Physiology, 214, 772.

ARborelius, M. JR (1969) Influence of unilateral hypoventilation on distribution of pulmonary blood flow in man. Journal of Applied Physiology, 26, 101.

Ball, W.C., JR., Stewart, P.B., Newham, L.G.S. \& Bates, D.V. (1962) Regional pulmonary function studied with xenon-133. Journal of Clinical Investigation, 41, 519.

Bass, H., Banas, J.S. \& DaleN, J.E. (1970) Pulmonary function studies. Archives of Internal Medicine, 126, 266. 
Bass, H. Heckscher, T. \& Anthonisen, N.R. (1967) Regional pulmonary gas exchange in patients with pulmonary embolism. Clinical Science, 33, 355.

Bates, D.V., Ball, W.C. JR \& Bryan, A.C. (1964) Use of xenon-133 in studying the ventilation and perfusion of the lung. In: Dynamic Clinical Studies with Radioisotopes (Ed. by R.M. Kniseley and W.N. TAWCE), p. 237. U.S.A.E.C. Division of Technical Information.

Bell, T.K., Ferguson, R., McIlrath, E.I. \& Weaver, J.A. (1968) Radioisotope scanning of the lungs. Thorax, 23, 24.

Bentivoglio, L.G., Beerel, F., Stewart, P.B., Bryan, A.C., BALL, W.C. JR \& BATES, D.V. (1963) Studies of regional ventilation and perfusion in pulmonary emphysema using xenon-133. American Review of Respiratory Diseases, 88, 315.

Bergofsky, E.H., Bass. B.G., Ferretti, R.\& Fishman, A.P. (1963) Pulmonary vasoconstriction in response to precapillary hypoxemia. Journal of Clinical Investigation, 42, 1201.

Blaisdell, W.F., Lim, R.C. JR, Amberg, J.R. Choy,, S.H., Hall, A.D. \& Thomas, A.N. (1966) Pulmonary microembolism. Archives of Surgery, 93, 776.

Bleik, A.J. \& BACHYNSKI, J.E. (1971) Two severe reactions following a pulmonary scan in a patient with idiopathic pulmonary hemosiderosis. Journal of Nuclear Medicine, $12,90$.

Bookstein, J.J. (1970) Pulmonary thromboembolism with emphasis on angiographic-pathologic correlation. Seminars in Roentgenology, 5, 291.

Brashear, R.E., Mishkin, F.S. \& Reese, I.C. (1969) Effects of iron (113mIn) hydroxide particles on pulmonary diffusing capacity and pulmonary artery pressure. Investigative Radiology, 4, 19.

Bryan, A.C., Bentivoglio, L.G., Beerel, F., Macleish, H., ZidulKa, A. \& BATES, D.V. (1964) Factors affecting regional distribution of ventilation and perfusion in the lung. Journal of Applied Physiology, 19, 395.

Burdine, J.A., Legeay, R., Ryder, L. \& Sonnemaker, R. (1969) Semiquantitative determination of dynamic events with a new scintillation camera. Journal of Nuclear Medicine, 10, 324.

Co-OPERATIVE Study (1970) Urokinase pulmonary embolism trial. Journal of the American Medical Association, 214, 2163.

Dalen, J.E., Banas, J.S. JR, Brooks, H.L., Evans, G.L., Parakos, J.A. \& DeXter, L. (1969) Resolution rate of acute pulmonary embolism in man. New England Journal of Medicine, 280, 1194.

DAvis, M.A. (1970) ${ }^{99 \mathrm{~m} T c}$ iron hydroxide aggregates; evaluation of a new lung scanning agent. Radiology, 95, 347.

Dawson, A. (1969) Regional pulmonary blood flow in sitting and supine man during and after acute hypoxia. Journal of Clinical Investigation, 48, 301.

DELAND, F.H. (1966) The fate of macroaggregated albumin used in lung scanning. Journal of Nuclear Medicine, 7, 883.

DeNardo, G.L., Goodwin, D.A., Ravasini, R. \& Dietrich P.A. (1970) The ventilatory lung scan in the diagnosis of pulmonary embolism. New England Journal of Medicine, 282, 1334

Duffy, G.J., DeNardo, G.L. \& Abington, R.B. (1968) Origin and evolution of radioactive pulmonary emboli in man. Radiology, 91, 1175.

Dworkin, H.J., SMith, J.R. \& Bull, F.E. (1966) Reaction after administration of macroaggregated albumin for a lung scan. New England Journal of Medicine, 275, 376.

Enson, Y., Giuntinı, C., Lewis, M.L., Morris, T.Q., FERRER, M.I. \& HaRveY, R.M. (1964) The influence of hydrogen ion concentration and hypoxia on the pulmonary circulation. Journal of Clinical Investigation, 43, 1146.
Fred, H.R., Burnine, J.A., Gonzales, D.A., Lockhart, R.W., Peabody, C.A. \& Alexander, J.K. (1966) Arteriographic assessment of lung scanning in the diagnosis of pulmonary embolism. New England Journal of Medicine, 275, 1026 .

Freeman, L.M., Zelefsky, M.N., Meng, C.H. \& KaPlan, N. (1968) The relative merits of lung scanning and angio-? graphy in the diagnosis of pulmonary embolism. Bulletin of the New York Academy of Medicine, 44, 1159.

Freiman, D.G., SuYemoto, J. \& Wessler, S.(1965) Frequency of pulmonary thromboembolism in man. New England $\stackrel{\mathrm{D}}{\overrightarrow{\mathrm{Q}}}$ Journal of Medicine, 272, 1278.

Friedman, W.F. \& Braunwald, E. (1966) Alterations in regional pulmonary blood flow in mitral valve disease $\overrightarrow{-}$ studied by radioisotope scanning. Circulation, 34, 363.

Furth, E.D., OKinaKa, A.J., FoCht, E.F. \& BeCKer, D.V. $\overrightarrow{\vec{\omega}}$ (1965) The distribution, metabolic fate and radiation dosimetry of ${ }^{131} \mathrm{I}$ labeled macroaggregated albumin. Journal of Nuclear Medicine, 6, 506.

GILDAY, D.L. \& JAMES, A.E. JR (1972) Lung scan patterns int? pulmonary embolism versus those in congestive heart $\vec{C}$ failure and emphysema. American Journal of Roentgenology, iv 115, 739 .

Gilday, D.L., Poulouse, K.P. \& Deland, F.L. (1972) Accuracy of detection of pulmonary embolism by lung $\subseteq$ scanning correlated with pulmonary angiography. American Journal of Roentgenology, 115, 732.

Gilson, A.J. \& SMOAK, W.M. III (1971) Pulmonary Investi-gation with Radionuclides. Charles C. Thomas, Springfield, $\subseteq$ Ill.

Gize, R., Dizon, M. \& Mishrin, F.S. Analysis of the fissuresign. Journal of Nuclear Medicine, 12, 822.

GoOdWIN, D.A., STERN, H.S. \& WAGNER, H.N. JR (1968) Ferric hydroxide particles labelled with ${ }^{118 m}$ In for lumg scanning. Journal of the American Medical Association, 2\&, 339.

Gottschalk, A., Usher, M.S., Turner, D.A., Polcyn, R.E.⿳亠口冋 \& QUINN, J.L. III (1971) The scintillation camera with diverging collimator; physical parameters and a clinicali evaluation. Seminars in Nuclear Medicine, 1, 206.

Hampton, A.O. \& Castleman, B. (1940) Correlation of post $\overline{\bar{O}}$ mortem chest teleroentgenograms with autopsy findings $; \exists$ pulmonary embolism and infarction. American Journal of Roentgenology, 43, 305.

HildNeR, F.J. \& ORMOND, R.S. (1967) Accuracy of the clinical diagnosis of pulmonary embolism. Journal of the American Medical Association, 202, 567.

Hopkins, G.B. (1972) Pulmonary angiothrombotic granulomatosis in drug offenders. Journal of the American Medica? Association, 221, 909.

James, A.E., Conway, J.J., Chang, C.H., Cooper, M.马 White, R.I. \& Strauss, H.W. (1971) The fissure sign its multiple causes. American Journal of Roentgenology? 111, 492.

JoHnson, P.M. (1971) The role of the lung scan in pulmonary embolism. Seminars in Nuclear Medicine, 1, 161.

Johnson, P.M., Parker, B.R., Cosgriff, S.W. \& Ellis, K (1969) Lung scanning in detecting pulmonary emboliq disease. New York State Journal of Medicine, 69, 2870.

KAFER, E.R. Respiratory function in pulmonary thrombow embolic disease. American Journal of Medicine, 47, 904. $O$

KenNADY, J.C. \& TAPLIN, G.V. Albumin macroaggregates for brain scanning: experimental basis and safety in primates. Journal of Nuclear Medicine, 6, 556.

KING, E.G., WoOD, D.E. \& Morley, T.P. (1966) Use of macroaggregates of radioiodinated human serum albuminin brain scanning. Canadian Medical Association Journal, 95,381 . 
KNISEly, W.H. \& KNISELY, M.H. (1954) Preliminary observations of the catch-trap architecture of pulmonary artery tips in health and their responses following distant somatic burns. Anatomical Records, 118, 320.

LloYd, T.C. JR (1966) Influence of blood pH on hypoxic pulmonary vasoconstriction. Journal of Applied Physiology, 21, 358.

LOKEN, M.K. (1971) Camera studies of lung ventilation and perfusion. Seminars in Nuclear Medicine, 2, 229.

Lopez-Majano, V. (1970) Regulation of pulmonary circulation. Progress in Respiratory Research, 5, 188.

Lopez-Majano, V., Chernick, V., Wagner, H.N. JR \& DutToN, R.E. (1964) Comparison of radioisotope scanning and differential oxygen uptake of the lungs. Radiology, 83, 697.

Lopez-Majano, V., Tow, D.E. \& Wagner, H.N. JR (1966) Regional distribution of pulmonary arterial blood flow in emphysema. Journal of the American Medical Association, $197,81$.

Lopez-Majano, V., Twining, R.H., Goodwin, D.A. \& WAGNER, H.N. JR (1967) Reproducibility of lung scans. Investigative Radiology 2, 410.

Mack, J.F., Wellamn, H.N., Saenger, E.L. \& Friedman, B.I. (1969) Clinical experience with oblique views in pulmonary perfusion camera imaging normal and pathological anatomy. Radiology, 92, 897.

McIntyre, K.M. \& SaSahara, A.A. (1971a) Hemodynamic alterations related to extent of lung scan perfusion defect in pulmonary embolism. Journal of Nuclear Medicine, 12 , 166.

McInTyre, K.M. \& Sasahara, A.A. (1971b) Correlation of pulmonary photoscan and angiogram as measures of the severity of pulmonary embolic involvement. Journal of Nuclear Medicine, 12, 732.

Milic-Emili, J. (1972) Radioactive xenon in the evaluation of regional lung function. Seminars in Nuclear Medicine, 2, 246.

MishKIN, F.S. (1968) The lateral view in lung scanning as an aid in differential diagnosis. Diseases of the Chest, 53, 743.

MISHKIN, F.S. \& BRASHEAR, R.E.(1971) Use and Interpretation of the Lung Scan. Charles C. Thomas, Springfield, Ill.

Mishkin, F.S., Brashear, R.E. \& ReESE, I.C. (1970) Evaluation of regional perfusion and ventilation using xenon-133 and the scintillation camera. American Journal of Roentgenology, 108, 60 .

Moser, K.M., Harsanyi, P., Ruis-Garriga, G., Guisan, M., Landis, G.A. \& Miale, A. JR (1969) Assessment of pulmonary photoscanning and angiography in experimental pulmonary embolism. Circulation, 39, 663.

Moser, K.M. \& MiALe, A. JR (1968) Interpretative pitfalls in lung photoscanning. American Journal of Medicine, 44, 366.

Moser, K.M., Tisi, G.M., Rhodes, P.G., Landis, G.A., \& Miale, A., JR (1966) Correlation of lung photoscans with pulmonary angiography in pulmonary embolism. American Journal of Cardiology, 18, 810.

Newhouse, M.T., Wright, F.J., Ingham, G.K., Archer, N.P., Hughes, L.B. \& Hopkins, O.L. (1968) Use of scintillation camera and xenon-135 for study of topographic function. Respiratory Physiology, 4, 141.

Poulouse, K.P., Reba, R.C. \& Wagner, H.N. JR (1968) Characterization of the shape and location of perfusion defects in certain pulmonary diseases. New England Journal of Medicine, 279, 1020.

QuinN, J.L. III (1971) Perfusion scanning in chronic obstructive lung disease. Seminars in Nuclear Medicine, 1, 185.

Rhodes, B.A., Zclle, I., Buchanan, J.W. \& Wagner, H.N. $J_{R}$ (1969) Radioactive albumin microspheres for studies of the pulmonary circulation. Radiology, 92, 1453.

Robin, E.D., Forkner, C.E. Jr, Bromberg, P.A., CrouTEAU, J.R. \& Travis, D.M. (1960) Alveolar gas exchange in clinical pulmonary embolism. New England Journal of Medicine, 262, 283.
Robin, E.D., Julian, D.G., Travis, D.M. \& Crump, C.H. (1959) A physiologic approach to the diagnosis of pulmonary embolism. New England Journal of Medicine, 260 , 586.

Rosenthall, L. (1965) Human brain scanning with radioiodinated macroaggregates of human serum albumin. Preliminary report. Radiology, 85, 110 .

Sasahara, A.A., Belko, J.S. \& Simpson, R.G. (1967a) Blended scintiscans of lungs with a dual detector system. Radiology, 88, 363.

Sasahara A.A., Cannilla, J.E., Belko, J.S., Morse, R.L. \& CRISS, A.J. (1967b) Urokinase therapy in clinical pulmonary embolism. New England Journal of Medicine, 277, 1168

Sashara, A.A., Cannilla, J.E., Morse, R.L., Sidd, J.J. \& Tremblay, G.M. (1967c) Clinical and physiologic studies in pulmonary thromboembolism. American Journal of Cardiology, 20, 10.

Simon, M. \& Sasahara, A.A. (1965) Observations on the angiographic changes in pulmonary thromboembolism. In: Pulmonary Embolic Disease (Ed. by A. A. Sasahara and M. Stein), p. 214. Grune and Stratton, New York.

Smith, G.T., DeXter, L. \& Dammon, G.J. (1965) Postmortem quantitative studies in pulmonary embolism. In: Pulmonary Embolic Disease (Ed. by A. A. Sasahara and M. Stein), p. 120. Grune and Stratton, New York.

SuRPRENANT, E. (1967) Lateral lung scanning; anatomic and physiologic considerations. American Journal of Roentgenology, 99, 533.

Swenson, E.W., Finley, T.N., Guzman, S.V. (1961) Unilateral hypoventilation in man during temporary occlusion of one pulmonary artery. Journal of Clinical Investigation, 40, 828.

Szucs, M.M. JR, Brooks, H.L., Grossman, W., Banas, J.S. JR, Meister, S.G., Dexter, L. \& Dalen, J.E. (1971) Diagnostic sensitivity of laboratory findings in acute pulmonary embolism. Annals of Internal Medicine, 74, 161.

Taplin, G.V., Johnson, D.E., Dore, E.K., \& KaPlan, H.S. (1964) Lung photoscans with macroaggregates of human serum albumin; experimental basis and initial clinical trials. Health Physics, 10, 1219.

Taplin, G.V., Johnson, D.E., Kennady, J.C., Dore, E.K. Poe, N.D., Swanson, L.A. \& GreenberG, A. (1966) Aggregated albumin labeled with various radioisotopes. In: Radioactive Pharmaceuticals (Ed. by G. A. Andrews, R. M. Kniseley and H. W. Wagner Jr), p. 525. A.E.C. Symposium Series 6, U.S.A.E.C. Division of Technical Information, Oak Ridge, Tennessee.

Tow, D.E. \& W AGNER, H.N. JR (1967) Recovery of pulmonary arterial blood flow in patients with pulmonary embolism. New England Journal of Medicine, 276, 1053.

Tow, D.E., WAGNer, H.N. JR \& Holmes, R.A. (1967) Urokinase in pulmonary embolism. New England Journal of Medicine, 277, 1161.

Tow, D.E., Wagner, H.N. JR, Lopez-Majano, V., Smith, E.M. \& Migita, T. (1966) Validity of measuring regional pulmonary arterial blood flow with macroaggregates of human serum albumin. American Journal of Roentgenology, 96, 644.

TWining, R.H., Lopez-Majano, V., Wagner, H.N. JR, Chernick, V. \& Dutton, R.E. (1968) Effect of regional hypercapnia on the distribution of pulmonary blood flow in man. Johns Hopkins Medical Journal, 123, 95.

Vincent, W.R., GoldberG, S.J. \& Desilets, D. (1968) Fatality immediately following rapid infusion of macroaggregates of ${ }^{80 \mathrm{~m}} \mathrm{Tc}$ albumin (MAA) for lung scan. Radio$\log y, 91,1181$.

WAGNER, H.N. JR (1968) Current status of lung scanning. Editorial. Radiology, 91, 1235. 
W agner, H.N. JR Sabiston, D.C. JR, McAfee, J.C., Tow, D.E. \& STERN, H.S. (1964) Diagnoses of massive pulmonary embolsim in man by radioisotope scanning. New England Journal of Medicine, 271, 377.

Wellman, H.N., Mack, J.F., Romhilt, D.W., Holmes, J.C., Gandel, P., SPITz, H.B. \& Fenton, J.C. (1973) Scintigraphy in screening pulmonary emboli-prospective comparison with angiography. In: Symposium on Scintigraphy Compared to Angiography, in press. Springer-Verlag, Heidelberg.

Wenger, N.K., Stein, P.D., Willis, P.W. III (1972) Massive acute pulmonary embolism. The deceivingly nonspecific manifestations. Journal of the American Medical Association, 220, 843.
WEST, J.B. (1970) The ventilation-perfusion concept. In: Pul-气ે monary Investigation with Radionuclides (Ed. by A. J. Gilson and W. M. Smolk III), p. 27. Charles C. Thomas, $\underset{\mathbb{Q}}{\mathbb{Q}}$ Springfield, Ill.

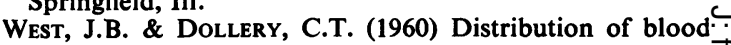
flow and ventilation-perfusion ratio in the lung, measured with radioactive $\mathrm{CO}_{2}$. Journal of Applied Physiology, 15, 405.

Wilson, J.E., Pierce, A.K., Johnson, R.L. JR., Winga, E.R.,음 Harrell, W.R., Curry, G.C. \& Mullins, C.B. (1971) Hypoxemia in pulmonary embolism; a clinical study. Journal of Clinical Investigation, 50, 481.

Winebright, J.W., Gerdes, A.J. \& NelP, W.B. (1970) Restoration of blood flow after pulmonary embolism. Archives of Internal Medicine, 125, 241. 